\title{
Making sense of disaster: affinity to God as a coping strategy of Muslim refugees in
} Central Sulawesi

\begin{abstract}
The present study aimed to uncover the essence of coping with natural disasters experienced by Muslim refugees. Fourteen refugees, who lived in three refugee camps in Central Sulawesi, were involved as informants. The findings revealed coping was essentially affected by informants' affinity to God. Individuals who had a stronger relationship with God were able to attribute more positive meaning to disaster and loss. Individuals who surrendered all matters to God were able to process the experience and develop acceptance. The result of religious coping from positive thinking, which is held first and foremost toward God, has protective effects on Muslim refugees.
\end{abstract}

Keyword: Coping strategy; Disaster; Muslim refugees 